\title{
Possible Involvement of the Cholinergic System in Hormonal Secretion by the Perfused Pancreas from Ventromedial-Hypothalamic Lesioned Rats
}

\author{
F. Rohner-Jeanrenaud and B. Jeanrenaud \\ Laboratoires de Recherches Métaboliques et Département de Médecine, Faculty of Medicine, Geneva, Switzerland
}

Summary. Total arginine-induced secretion of insulin, glucagon and somatostatin was studied during a $20 \mathrm{~min}$ period in isolated perfused pancreases from control and non-hyperphagic ventromedial hypothalamic (VMH) lesioned rats. Compared to controls pancreases from VMH-lesioned rats secreted more insulin ( $82 \pm 13 \mathrm{ng}$ vs $36 \pm 9 \mathrm{ng}$ ) and more glucagon $(130 \pm 23 \mathrm{ng}$ vs $73 \pm 14 \mathrm{ng})$ but less somatostatin $(0.58 \pm 0.18 \mathrm{ng}$ vs $1.12 \pm 0.14 \mathrm{ng})$. These abnormalities were restored to normal by perfusion with atropine $(25 \mu \mathrm{mol} / \mathrm{l})$. Pancreases of both groups were perfused with the cholinergic agonist methacholine $(100 \mu \mathrm{mol} / 1)$. Again pancreases from VMH-lesioned rats secreted more insulin ( $157 \pm 19 \mathrm{ng}$ vs $33 \pm 6 \mathrm{ng}$ ) and more glucagon ( $95 \pm 13 \mathrm{ng}$ vs $57 \pm 9 \mathrm{ng}$ ) but less somatostatin $(0.80 \pm 0.15 \mathrm{ng}$ vs $1.30 \pm 0.18 \mathrm{ng})$. These results support the concept that, in pancreases isolated from VMH-lesioned rats increased "cholinergic activity" may prevail via increased release of endogenous acetylcholine from islet-postsynaptic ganglion cells together with increased numbers of muscarinic receptors on postsynaptic ganglion cells as well as on endocrine cells.

Key words: Ventromedial hypothalamus (VMH), isolated perfused pancreas, insulin secretion, glucagon secretion, somatostatin secretion, methacholine, atropine

Chemical or electrolytic destruction of the ventromedial hypothalamus (VMH) results in many disturbances, of which hyperphagia and hyperinsulinaemia are the most prominent [1]. While increased food intake has long been taken as the major change of VMH-lesioned animals, increased insulin secretion is now considered of greater importance in the development of the VMH-syndrome. Indeed, hyperinsulinaemia and obesity have been shown to develop independently of hyperphagia [2-5].
Increased insulin secretion occurs in vivo within minutes after lesions of the VMH-area of anaesthetized rats, clearly unrelated to any change in food intake [6]. Recently, it has been shown that insulin and glucagon secretion by perfused pancreases obtained from VMH-lesioned rats pair-fed to controls were increased compared to that of normal rats, although the biphasic pattern of both secretions was unmodified [7]. Insulin and glucagon secretion are known to be under the control of both the sympathetic and the parasympathetic nervous system $[8,9]$. In this respect, one should note that hyperinsulinaemia that follows acute destruction of the VMH-area can be normalised by superimposed acute bilateral subdiaphragmatic vagotomy [10]. This suggests that the vagus nerve plays a role in bringing about the over-secretion of insulin.

Although inhibition of insulin and glucagon secretion by exogenous somatostatin is well substantiated [11], little is known about its role when released endogenously, or its possible regulation by the autonomic nervous system, particularly in the VMH-syndrome.

The aims of this study were: a) to further investigate the consequences of prior electrolytic lesions of the ventromedial hypothalamus not only upon insulin and glucagon but also on somatostatin release by the isolated perfused pancreas, using the substrate, arginine, known to increase the secretion of these three hormones in the normal pancreas $[17,18]$; b) to determine whether the hormonal alterations observed in the pancreas from VMH-lesioned rats could involve the cholinergic nervous system.

\section{Materials and Methods}

\section{Animals}

Eight to ten-week old female Wistar rats, weighing between 200 and $240 \mathrm{~g}$ and bred in these laboratories were used. They were kept in animal quarters with constant temperature $\left(23^{\circ} \mathrm{C}\right)$ and 
fixed (12 h) light cycle. The animals were fed with standard laboratory chow (UAR Laboratories, Villemoisson, Epinay/Orge, France) according to the protocol outlined below.

\section{Experimental Design}

Rats were anaesthetized with ketamine hydrochloride $(80 \mathrm{mg} / \mathrm{kg}$ body weight). Stereotaxically guided, bilateral electrolytic lesions of the ventromedial hypothalamic area (VMH), and perfusion of the isolated pancreas were performed as described in detail elsewhere $[6,7,12]$. Prior to perfusion, the following protocol was adopted:

On recovery from the anaesthetic both control and VMHlesioned rats were fed ad libitum for three days in order to select successful lesions of the hypothalamus by the occurrence of hyperphagia and increased body weight (mean excess in body weight over controls after 3 days, $36 \pm 2 \mathrm{~g}$ ). Following this, control and VMH-lesioned rats received for 4 days the same amount of food ( $16 \mathrm{~g}$ per day) given at identical time intervals by an automatic food distributor. Pancreases of both groups were then isolated and perfused with a non-recirculating medium gassed with $\mathrm{O}_{2} / \mathrm{CO}_{2}$ mixture (95:5). The perfusion medium was a Krebs-Ringer bicarbonate buffer, $\mathrm{pH} 7.4-7.5$, containing $0.25 \mathrm{~g} / 100 \mathrm{ml}$ human serum albumin (Red Cross, Berne, Switzerland) and Iniprol (2000 antiprotease units per millilitre, Laboratoire Choay, 75016 Paris, France). In the first series of experiments, the perfusion medium contained no glucose, and after a $30 \mathrm{~min}$ equilibration period, the pancreases of normal and VMH-lesioned rats were challenged for $20 \mathrm{~min}$ with either arginine alone $(10 \mathrm{mmol} / \mathrm{l})$, or arginine plus the cholinergic (muscarinic) inhibitor, atropine $(25 \mu \mathrm{mol} / \mathrm{l})$. In the second series of experiments, the perfusion medium contained $2.5 \mathrm{mmol} / 1$ glucose, and following the $30 \mathrm{~min}$ equilibration period, the pancreases were challenged for $20 \mathrm{~min}$ with either the cholinergic (muscarinic) agonist, methacholine $(100 \mu \mathrm{mol} / 1)$, or with methacholine plus atropine $(25 \mu \mathrm{mol} / \mathrm{l})$. In both cases, in order to obtain information about total hormonal outputs during the $20 \mathrm{~min}$ period, the whole effluent was collected at $4^{\circ} \mathrm{C}$ for subsequent radioimmunoassay measurements. Aliquots of effluent, stored at $-20^{\circ} \mathrm{C}$, were analyzed for insulin according to Herbert et al. [13] using rat insulin as a standard, for glucagon according to Unger et al. [14] using the $30 \mathrm{~K}$ antibody specific for pancreatic glucagon and with porcine-glucagon as standard, for somatostatin according to Schauder et al. [15] using our own antibody and synthetic cyclic somatostatin as standard. The somatostatin antiserum was raised in rabbits by immunisation with synthetic cyclic somatostatin conjugated to bovine serum albumin with 1-ethyl-3(3-dimethylamino-propyl) carbodiimide. This antiserum showed no cross-reactivity with insulin, glucagon, pancreatic poly- peptide, gastric inhibitory polypeptide, vasoactive intestinal polypeptide, gastrin, motilin, secretin or cholecystokinin-pancreozymin (cross-reactivity studies carried out by Dr: J. Ardill, Queen's University, Belfast, U.K.). With this antiserum at a dilution of $1: 6000$, the minimum detectable dose as determined by the amount for the lower limit of $95 \%$ confidence limits of the buffer control was $4 \mathrm{pg} /$ tube. Within-assay coefficient of variation was $9.8 \%$.

Rat insulin standard and pork glucagon standard were both secured from Novo Research Institute (Bagsvaerd, Denmark); cyclic somatostatin and N-tyrosylated somatostatin from Serono (Freiburg, West Germany). Guinea-pig antipork insulin serum was obtained from Miles-Yeda Ltd. (Rehovoth, Israel). 30K glucagon antiserum was purchased from Dr. R. Unger (Dallas, U.S.A.)

All organic and inorganic chemicals were of analytical grade and purchased from Merck AG (Darmstadt, West Germany) or from Sigma Chemical Co. (St. Louis, U.S.A.).

The Student $t$ test for unpaired data was used throughout the study for comparison of mean values.

\section{Results}

The amount of insulin and glucagon released during the $20 \mathrm{~min}$ stimulation period in the presence of arginine was higher in perfused pancreases from VMH-lesioned rats than in controls (Fig. 1). For both insulin and glucagon, basal release (i.e., without addition of arginine) was not different between the groups (Table 1). Basal secretion of somatostatin was identical (Table 1), but pancreases from VMHlesioned rats secreted less somatostatin than controls during arginine infusion (Fig. 1). Indeed, the addition of arginine produced the expected increase in somatostatin release in control pancreases while it resulted in an inhibitory effect in pancreases from VMH-lesioned rats (Table 1).

The addition of atropine did not alter the arginine-induced secretion of insulin, glucagon or somatostatin by pancreases of control rats, the small apparent increase in insulin and glucagon, and decrease in somatostatin being insignificant (Table 1). In contrast, atropine decreased the high arginine induced output of insulin and glucagon observed in

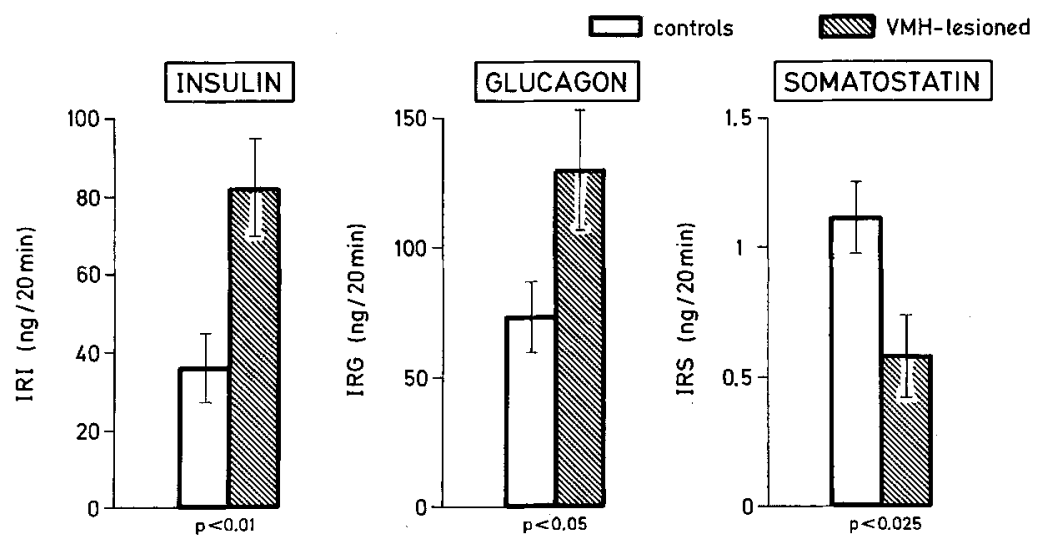

Fig. 1. Effect of arginine on insulin, glucagon and somatostatin secretion by perfused pancreases of control and food-restricted ventromedial hypothalamic (VMH)-lesioned rats. Perfusion medium was a glucose-free Krebs-Ringer bicarbonate buffer with $10 \mathrm{mmol} / \mathrm{l}$ arginine. Each bar is the mean of 4-6 perfusions \pm SEM, with statistical significance as indicated by the $p$ values 
Tahle 1. Basal and arginine-induced insulin, glucagon and somatostatin secretion by pancreases from control and non-hyperphagic ventromedial hypothalamic (VMH)-lesioned rats perfused in the absence and in the presence of atropine

\begin{tabular}{lccc}
\hline & $\begin{array}{l}\text { Insulin output } \\
(\mathrm{ng} / 20 \mathrm{~min})\end{array}$ & $\begin{array}{c}\text { Glucagon output } \\
\text { (ng/20 min) }\end{array}$ & $\begin{array}{c}\text { Somatostatin output } \\
\text { (ng/20 min) }\end{array}$ \\
\hline Control (basal) & $5 \pm 0.4$ & $24 \pm 6$ & $0.88 \pm 0.11$ \\
Control + arginine & $36 \pm 9$ & $73 \pm 14$ & $1.12 \pm 0.14$ \\
Control + arginine + atropine & $45 \pm 12$ & $110 \pm 28$ & $0.75 \pm 0.13$ \\
VMH-lesioned (basal) & $8 \pm 2$ & $40 \pm 9$ & $0.88 \pm 0.08$ \\
VMH-lesioned + arginine & $82 \pm 13$ & $130 \pm 23$ & $0.58 \pm 0.18$ \\
VMH-lesioned + arginine + atropine & $41 \pm 14$ & $56 \pm 4$ & $1.30 \pm 0.20$ \\
\hline
\end{tabular}

Perfusion medium was a glucose-free Krebs-Ringer bicarbonate buffer. Measurements were made after a 30 min equilibration period. Arginine used at $10 \mathrm{mmol} / 1$ and atropine at $25 \mu \mathrm{mol} / 1$. Values are means of $4-6$ perfusions $\pm \mathrm{SEM}$

Controls + arginine versus controls + arginine and atropine for all conditions tested: not significant

Controls versus VMH-lesioned with arginine stimulation: for insulin, glucagon and somatostatin, significantly different at least at $\mathbf{p}<0.05$ VMH-lesioned + arginine versus VMH-lesioned + arginine and atropine: insulin, glucagon and somatostatin, significantly different from each other at least at $\mathrm{p}<0.05$

Other differences were not significant

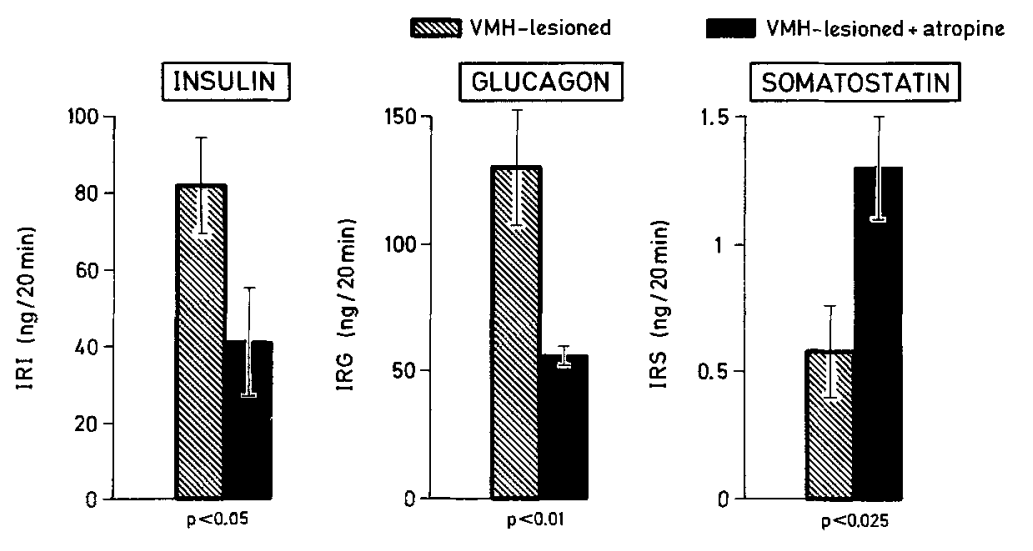

\begin{abstract}
Fig. 2. Effect of atropine on arginine-induced insulin, glucagon and somatostatin secretion by perfused pancreases of food-restricted ventromedial hypothalamic (VMH)-lesioned rats. Experimental conditions as in Figure 1, with or without atropine $(25 \mu \mathrm{mol} / 1)$. Each bar is the mean of $4-6$ perfusions \pm SEM, with statistical significance as indicated by the $p$ values
\end{abstract}

pancreases from VMH-lesioned rats (Fig. 2). Furthermore the low somatostatin secretion from the pancreases of these animals was increased by atropine (Table 1).

As shown (Fig. 3), the amount of insulin released during a 20 min methacholine infusion was markedly higher in pancreases from VMH-lesioned rats than in controls. These effects appeared to be specific for the cholinergic system since they were completely abolished by the superimposed infusion of atropine. Basal insulin secretion (i.e., no methacholine) was similar in the two groups (Table 2). Analogous results were obtained for glucagon release which was again higher in pancreases from VMH-lesioned rats than in controls. However, in this study basal glucagon secretion rate was significantly higher in pancreases from VMH-lesioned rats compared to controls and was therefore contributing to the difference in total output observed between control and VMHlesioned rats during methacholine infusion (Table 2). As in the case of insulin, increase in methacholine- induced glucagon secretion by pancreases of VMHlesioned rats was markedly curtailed by superimposed addition of atropine. Finally pancreases from VMH-lesioned rats secreted somewhat less somatostatin than controls over the $20 \mathrm{~min}$ period in the presence of methacholine (Fig. 5) in spite of identical baseline values (Table 2), an effect that was normalised by atropine. The release of somatostatin by control pancreases was unaffected by methacholine, with or without atropine (Fig. 5, Table 2).

\section{Discussion}

Work from these laboratories has previously shown that the biphasic pattern of glucose-induced insulin and arginine-induced glucagon secretion was unaltered in pancreases from non-hyperphagic ventromedial hypothalamic (VMH) lesioned rats but that the release of these hormones was quantitively greater than that of control pancreases $[7,16]$. The aim of 


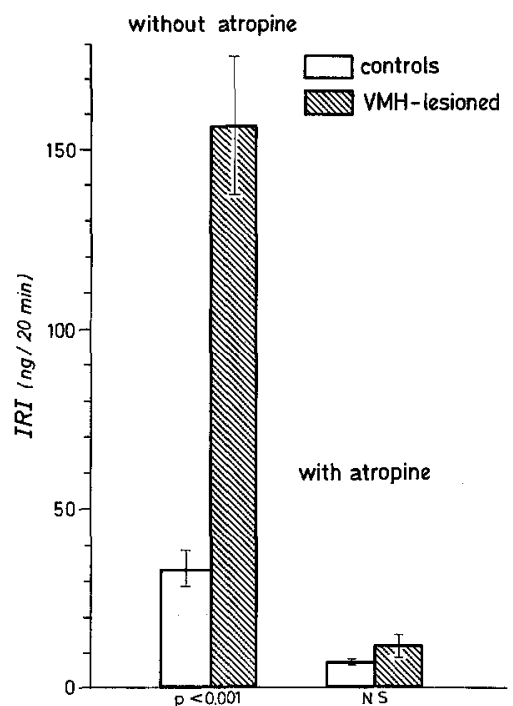

Fig. 3. Effect of methacholine on insulin secretion by perfused pancreases of control and food-restricted ventromedial hypothalamic (VMH)-lesioned rats. Perfusion medium was a Krebs-Ringer bicarbonate buffer containing glucose $(2.5 \mathrm{mmol} / 1)$, methacholine $(100 \mu \mathrm{mol} / \mathrm{l})$, with or without atropine $(25 \mu \mathrm{mol} / 1)$. Each bar is the mean of 7-9 perfusions \pm SEM, with statistical significance as indicated by the $\mathrm{p}$ values

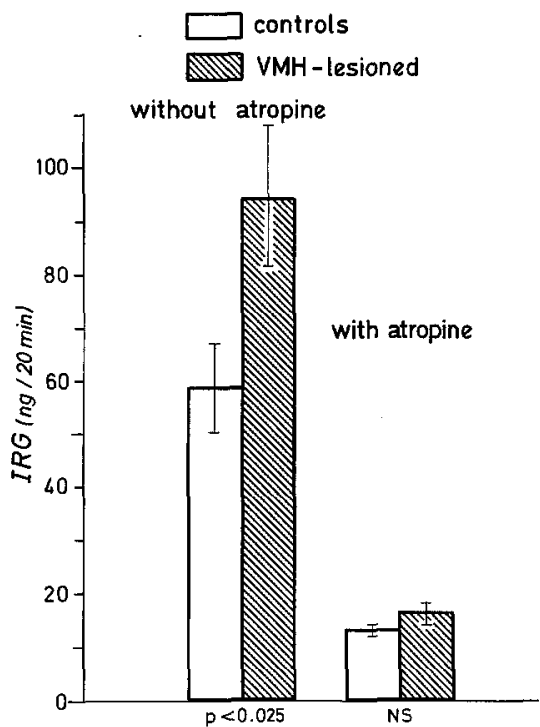

Fig. 4. Effect of methacholine on glucagon secretion by perfused pancreases of control and food-restricted ventromedial hypothalamic (VMH)-lesioned rats. Experimental conditions as in Figure 3. Each bar is the mean of 7-9 perfusions \pm SEM, with statistical significance as indicated by the $p$ values

Table 2. Basal and methacholine-induced insulin, glucagon and somatostatin secretion by pancreases from control and non-hyperphagic ventromedial hypothalamic (VMH)-lesioned rats perfused in the absence and in the presence of atropine

\begin{tabular}{lccc}
\hline & $\begin{array}{l}\text { Insulin output } \\
\text { (ng/20 min) }\end{array}$ & $\begin{array}{l}\text { Glucagon output } \\
\text { (ng/20 min) }\end{array}$ & $\begin{array}{l}\text { Somatostatin output } \\
\text { (ng/20 min) }\end{array}$ \\
\hline Control (basal) & $15 \pm 3$ & $15 \pm 2$ & $1.17 \pm 0.27$ \\
Control + methacholine & $33 \pm 6$ & $57 \pm 9$ & $1.30 \pm 0.18$ \\
Control + methacholine and atropine & $7 \pm 1$ & $13 \pm 1$ & $1.20 \pm 0.17$ \\
VMH-lesioned (basal) & $16 \pm 6$ & $36 \pm 9$ & $1.16 \pm 0.20$ \\
VMH-lesioned + methacholine & $157 \pm 19$ & $95 \pm 13$ & $0.80 \pm 0.15$ \\
VMH-lesioned + methacholine and atropine & $12 \pm 2$ & $16 \pm 2$ & $1.30 \pm 0.14$ \\
\hline
\end{tabular}

Perfusion medium was a Krebs-Ringer bicarbonate buffer with glucose $(2.5 \mathrm{mmol} / 1)$. Values are means of $7-9$ perfusions $\pm S E M$. Methacholine, $100 \mu \mathrm{mol} / 1$ and atropine, $25 \mathrm{umol} / 1$. Measurements were made after a $30 \mathrm{~min}$ equilibration period

Controls + methacholine versus controls + methacholine and atropine: for insulin and glucagon, significantly different at least at $p<0.05$. Other differences: not significant

Controls + methacholine versus VMH-lesioned + methacholine: for insulin, glucagon and somatostatin, significantly different at least at $\mathrm{p}<0.05$

VMH-lesioned + methacholine versus VMH-lesioned + methacholine and atropine: for insulin, glucagon and somatostatin, significantly different at least at $\mathrm{p}<0.05$

Control basal versus VMH-lesioned basal significantly different $(\mathrm{p}<0.05)$ only for glucagon

this study was to investigate further the consequences of prior hypothalamic lesions upon the secretory activity of subsequently perfused pancreases. Initially, a stimulus able to augment, in normal pancreases, the secretion of insulin, glucagon and somatostatin was searched, and one was found to be adequate in doing so, namely arginine as discovered by other laboratories $[17,18]$. A comparison of the total output of these three hormones in perfused pancreases from normal and non-hyperphagic VMH- lesioned rats could therefore be carried out. The striking observation made during the present experiments was that the overall, arginine-induced secretion of both insulin and glucagon was greater, while that of somatostatin was smaller, in pancreases from VMH-lesioned animals when compared to controls (Fig. 1). The experiments just mentioned were performed in the absence of glucose in the medium. This situation has been reported to result in a massive release of norepinephrine [19] which could, in turn, 


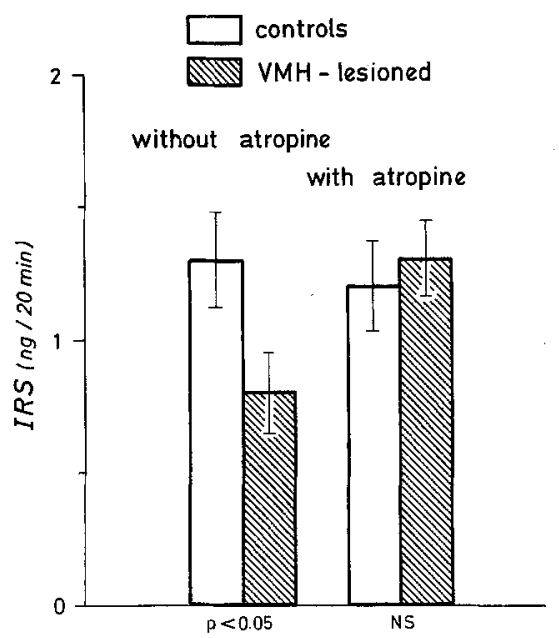

Fig. 5. Effect of methacholine on somatostatin secretion by perfused pancreases of control and food-restricted ventromedial hypothalamic (VMH)-lesioned rats. Experimental conditions as in Figure 3. Each bar is the mean of 7-9 perfusions \pm SEM, with statistical significance as indicated by the $p$ values

stimulate glucagon output [19] and inhibit somatostatin release [20]. Conceivably, such situation could be even more pronounced in pancreases from VMHlesioned rats than in controls in view of the putative increased number of adrenergic receptors [7]. Although this interpretation of the results obtained above cannot be completely ruled out it appears, however, unlikely as such adrenergic discharge is not compatible with the observed increase in insulin secretion.

Hypertrophy and hyperplasia of the islets of Langerhans have been reported to occur within a few days after VMH lesions, even when hyperphagia was prevented [4]. Hypersecretion of insulin and glucagon by pancreases from VMH-lesioned animals in response to arginine could conceivably be attributed to an increase in the B-and A-cell mass which would not necessarily be detected through higher baseline secretory values. However, the low arginine-induced somatostatin output by pancreases from $\mathrm{VMH}-$ lesioned rats compared to controls cannot easily be explained on the basis of an increased D-cell mass, as it was even lower than the basal somatostatin secretion rate (Table 1). As mentioned in the introduction, hyperinsulinaemia produced by acute electrolytic lesions of the VMH of normal anaesthetized rats was abolished by superimposed vagotomy [10]. In this respect, it should be stressed that fibres from the vagus nerve enter the pancreas in the mixed pancreatic nerve and synapse, within the islets, with ganglion cells that release acetylcholine in the vicinity of any secretory cell type [21]. Moreover, it has been demonstrated that acetylcholine stimulates insulin and glucagon release $[8,9,22]$, and that these effects, in perfused canine pancreases, can be abolished by the infusion of atropine used at $25 \mu \mathrm{mol} / 1$ [22]. Acetylcholine has also been shown to inhibit somatostatin release in perfused pancreases of normal dogs [23, 24]. Lack of such inhibition [25] has been reported, and been tentatively attributed to an abnormally low calcium concentration used in the perfusion medium.

Based on the above-mentioned observations made in normal animals, it can be hypothetized that the changes observed in the secretory activity of perfused pancreases from VMH-lesioned rats could be related to an overall increased "cholinergic activity". To test this hypothesis, pancreases challenged by arginine were perfused with or without atropine. In pancreases of normal rats, no significant changes in the release of any one of the three hormones measured could be detected in the presence of the anticholinergic drug. In marked contrast, perfusion of pancreases from VMH-lesioned rats with the cholinergic blocking agent, atropine, clearly resulted in marked decreases in the secretion of both insulin and glucagon, concomitant with an increase in that of somatostatin (Fig. 2).

In view of the existence of unspecific effects of atropine, when used at a high concentration, on receptor sites other than the muscarinic ones, on norepinephrine, histamine and 5-hydroxy-tryptamine receptors in particular [26], the specificity of the drug was further tested in our system by using the muscarinic receptor agonist, methacholine. Methacholine produced greater output of insulin and glucagon in perfused pancreases from VMH-lesioned rats than in controls (Figs. 3, 4). On the contrary, somatostatin release as induced by methacholine was significantly less in pancreases from VHM-lesioned rats than in controls (Fig. 5). Of note was that the changes induced by the presence of methacholine were all abolished upon addition of atropine, indicating that the drug, as used in this study, had specific anti-cholinergic effects.

The overall results of this study therefore suggest two possible abnormalities in pancreases obtained from semi-chronically ( 7 days) VMH-lesioned rats: the first would be the persistence of an increased "cholinergic activity", possibly due to the presence of overactive (via unknown mechanism) post-synaptic ganglion cells within the islets of Langerhans; such alteration would fit the arginine-induced, atropineinhibitable oversecretion of insulin and glucagon, and undersecretion of somatostatin observed in pancreases from VMH-lesioned rats. The second alteration could be related to a putative trophic effect of vagus nerves rendered "hyperactive" by the VMH 
lesions. This could result in increased islet endocrineand ganglion-cell mass, together with an absolute or relative increase in the number of muscarinic receptors of those cells. The methacholine experiments would be in keeping with such an hypothesis. Mechanistically, it is conceivable that the low somatostatin release found in pancreases from VMHlesioned animals could be partly responsible for the high output of both insulin and glucagon in the two experimental conditions used in this study. Similarly, insulin and glucagon secretion by control pancreases could be restrained by the observed higher release of somatostatin. Such paracrine function of the D-cells is, however, only hypothetical, and the overall changes in the secretory activity of the endocrine pancreas of a VMH-lesioned animal could be related solely to augmented "cholinergic activity" influencing the A-, B- and D-cells individually, without implicating intercellular relationships.

Acknowledgements. We are grateful to Miss Christine Grillet for her expert technical assistance.

This work was supported by grant 3.951 .080 of the Swiss National Science Foundation, Berne, by a grant-in-aid of Nestlé S.A., Vevey, Switzerland, and by grant 1 ROl AM25220-01 of the National Institutes of Health, Bethesda, MD, U.S.A.

\section{References}

1. Assimacopoulos-Jeannet F, Jeanrenaud B (1976) The hormonal and metabolic basis of experimental obesity. Clin Endocrinol Metab 5: 337-365

2. Han PW (1967) Hypothalamic obesity in rats without hyperphagia. Trans N Y Acad Sci 30: 229-243

3. Frohman LA, Bernardis LL, Schnatz JD, Burek L (1969) Plasma insulin and triglyceride levels after hypothalamic lesions in weanling rats. Am J Physiol 216: 1496-1501

4. Martin JM, Konijnendijk W, Bouman PR (1974) Insulin and growth hormone secretion in rats with ventromedial hypothalamic lesions maintained on restricted food intake. Diabetes 23: 203-208

5. Karakash C, Hustvedt BE, Løvø A, Le Marchand Y, Jeanrenaud $B$ (1977) Consequences of ventromedial hypothalamic lesions on metabolism of perfused rat liver. Am J Physiol 232: E286-E293

6. Rohner F, Dufour AC, Karakash C, Le Marchand Y, Ruf KB, Jeanrenaud B (1977) Immediate effect of lesion of the ventromedial hypothalamic area upon glucose-induced insulin secretion in anaesthetized rats. Diabetologia 13: 239-242

7. Rohner-Jeanrenaud F, Jeanrenaud B (1980) Consequences of ventromedial hypothalamic lesions upon insulin and glucagon secretion by subsequently isolated perfused pancreases in the rat. J Clin Invest 65: 902-910

8. Porte D Jr, Girardier L, Seydoux J, Kanazawa Y, Posternak J (1973) Neural regulation of insulin secretion in the dog. J Clin Invest 52: 210-214

9. Woods SC, Porte D Jr (1974) Neural control of the endocrine pancreas. Physiol Rev 54: 596-619

10. Berthoud H-R, Jeanrenaud B (1979) Acute hyperinsulinemia and its reversal by vagotomy following lesions of the ven- tromedial hypothalamus in anaesthetized rats. Endocrinology 105: 146-151

11. Assan R (1976) La somatostatine: une nouvelle hormone? Diabète Métab 2: 135-146

12. Assan R, Attali JR, Ballerio G, Baillot J, Girard JR (1977) Glucagon secretion induced by natural and artificial amino acids in the perfused rat pancreas. Diabetes 26: 300-307

13. Herbert V, Lau KS, Gottlieb CW, Bleicher SJ (1973) Coated charcoal immunoassay of insulin. J Clin Endocrinol Metab 25: 1375-1384

14. Unger RH, Aguilar-Parada E, Müller WA, Eisentraut AM (1970) Studies of pancreatic alpha-cell function in normal and diabetic subjects. J Clin Invest 49: 837-848

15. Schauder P, McIntosh C, Arends J, Arnold R, Frerichs H, Creutzfeldt W (1977) Somatostatin and insulin release from isolated rat pancreatic islets in response to D-glucose, L-leucine, $\alpha$-ketoisocaproic acid or D-glyceraldehyde: evidence for a regulatory role of adenosine- $3^{\prime}, 5^{\prime}$-cyclic monophosphate. Biochem Biophys Res Commun 75: 630-635

16. Rohner F (1977) Hypersecretion of insulin in perfused pancreas of rats with hypothalamic lesions. Diabetologia 13: 428

17. Patton GS, Ipp E, Dobbs RE, Vale W, Orci L, Unger RH (1976) Response of pancreatic immunoreactive somatostatin to arginine. Life Sci 19: 1957-1960

18. Efendic S, Nylen A, Roovete A, Uvnäs-Wallensten K (1978) Effects of glucose and arginine on the release of immunoreactive somatostatin from the isolated perfused rat pancreas. FEBS Lett 92: 33-35

19. Christensen NJ, Iversen J (1973) Release of large amounts of noradrenaline from the isolated perfused canine pancreas during glucose deprivation. Diabetologia 9: 396-399

20. Samols E, Weir GC (1979) Adrenergic modulation of pancreatic A, B and D cells. $\alpha$-adrenergic suppression and $\beta-$ adrenergic stimulation of somatostatin secretion, $\alpha$-adrenergic stimulation of glucagon secretion in the perfused dog pancreas. J Clin Invest 63: 230-238

21. Woods SC, Porte D (1978) The central nervous system, pancreatic hormones, feeding, and obesity. In: Levine R (ed) Advances in metabolic disorders. Academic Press, New York, p 283-312

22. Iversen J (1973) Effect of acetyl choline on the secretion of glucagon and insulin from the isolated, perfused canine pancreas. Diabetes 22: 381-387

23. Samols E, Weir G, Patel Y, Loo S, Gabbay K (1977) Autonomic control of somatostatin and pancreatic polypeptide secretion by the isolated perfused canine pancreas. Clin Res 25: $499 \mathrm{a}$

24. Samols E, Weir GC, Ramseur R, Day JA, Patel YC (1978) Modulation of pancreatic somatostatin by adrenergic and cholinergic agonism and by hyper- and hypoglycemic sulfonamides. Metabolism 27 [Suppl I]: 1219-1221

25. Hermansen K, Christensen SE, Ørskov H (1979) Characterisation of somatostatin release from the pancreas. The role of calcium and acetylcholine. Diabetologia 16: 261-266

26. Goodman LS, Gilman A (1975) In: The pharmacological basis of therapeutics, fifth ed. Macmillan publishing, New York, $p$ 514-532

Received: October 3, 1979,

and in revised form: October 9, 1980

Dr. Françoise Rohner-Jeanrenaud

Laboratoires de Recherches Métaboliques

64, Avenue de la Roseraie

CH-1205 Geneva

Switzerland 